\title{
Nursing actions for overweight and obese children in the Family Health Strategy
}

\author{
Ações de enfermagem às crianças com sobrepeso e obesidade na Estratégia Saúde da \\ Família
}

Adicéa de Souza Ferreira ${ }^{1}$, Juliana Rezende Montenegro Medeiros de Moraes $^{2}$, Fernanda Garcia Bezerra de Góes ${ }^{3}$, Liliane Faria da Silva ${ }^{3}$, Priscilla Valladares Broca², Sabrina da Costa Machado Duarte ${ }^{2}$

Objective: to analyze the actions of nurses in the follow-up of the growth and development of overweight and obese children in the Family Health Strategy. Methods: qualitative research, developed through a semistructured interview with 12 nurses from five Family Health Clinics whose data were submitted to thematic analysis. Results: nurses carry out anthropometric follow-up and analysis of these data in the health booklet, provide guidance on breastfeeding and the importance of a balanced diet for children and families, and their actions are carried out in Family Health Clinics, schools and homes. Conclusion: the nursing actions are focused on the child and the family's self-care in order to prevent or minimize the effects of overweight and obesity in childhood and its repercussions for adult life.

Descriptors: Obesity; Overweight; Child Health; Nursing; Family Health Strategy.

Objetivo: analisar as ações de enfermeiros no acompanhamento do crescimento e desenvolvimento de crianças com sobrepeso e obesidade na Estratégia Saúde da Família. Métodos: pesquisa qualitativa, desenvolvida por meio de entrevista semiestruturada com 12 enfermeiros de cinco Clínicas de Saúde da Família cujos dados foram submetidos à Análise Temática. Resultados: os enfermeiros fazem acompanhamento antropométrico e análise desses dados na caderneta de saúde, orientam sobre o aleitamento materno e a importância de dieta balanceada para crianças e famílias, tendo as suas ações realizadas nas clínicas de saúde da família, nas escolas e nos domićlios. Conclusão: as ações de enfermagem estão voltadas para o autocuidado da criança e da família com intuito de prevenir ou minimizar os efeitos do sobrepeso e obesidade na infância e suas repercussões para a vida adulta.

Descritores: Obesidade; Sobrepeso; Saúde da Criança; Enfermagem; Estratégia Saúde da Família.

\footnotetext{
1Prefeitura de Petrópolis. Petrópolis, RJ, Brazil.

${ }^{2}$ Universidade Federal do Rio de Janeiro. Rio de Janeiro, RJ, Brazil.

${ }^{3}$ Universidade Federal Fluminense. Rio das Ostras, RJ, Brazil.
}

Corresponding author: Juliana Rezende Montenegro Medeiros de Moraes

Rua Afonso Cavalcanti, 275 - Cidade Nova, CEP: 20211-160. Rio de Janeiro, RJ, Brazil. E-mail: jumoraes333@gmail.com 


\section{Introduction}

In the last decades, childhood obesity has become a major public health problem in several countries, being considered a worldwide epidemic, with a higher prevalence in families with lower income. In Australia, the United States, France, the United Kingdom and Canada, more than a quarter $(27.0 \%)$ of poor children are overweight or obese compared to less than one fifth $(19.0 \%)$ of socioeconomically most favored children $^{(1)}$.

In Brazil, an epidemiological transition from a scenario of malnourished children to those overweight and obese began in the $1990^{\prime}{ }^{(2-3)}$. Research conducted in a state in southern Brazil, between 2014 and 2016 , identified overweight in $18.2 \%$ of boys and $92.1 \%$ of girls, among 675 adolescents $^{(3)}$. In Minas Gerais, among children served in the Family Health Strategy, overweight was $17.5 \%$ and obesity was $25.0 \%$ among girls; and $4.3 \%$ overweight and $13.0 \%$ obesity among boys ${ }^{(4)}$.

Childhood obesity can lead to problems in children's health, such as musculoskeletal disorders, dyslipidemia, hypertension, and diabetes mellitus ${ }^{(3,5)}$. Therefore, excess body weight is associated with increased morbidity and mortality in childhood and adulthood, being a predisposing factor for cardiovascular diseases, metabolic syndrome, and chronic-degenerative diseases, which has concerned health professionals ${ }^{(6)}$. In addition to the physical repercussions, obesity and overweight can also cause other disorders such as poor self-image and difficulty in social interaction due to fear of prejudice and stigmatization, and increased susceptibility of children to be bullied, which impacts throughout one's life $\mathrm{e}^{(1,3-5)}$.

Such overweight conditions in childhood originate from the imbalance of self-care between child and family, with an intake of food calories greater than the caloric expenditure. This excessive consumption of food may be due to the supply of caloric foods in the home and school environment, excessive dedication of parents to work, leading to a greater supply of semi-prepared foods, the contemporary lifestyle, reduced practice of physical activities, and the greater time in front of the computer and television ${ }^{(7-8)}$.

Considering that child overweight and obesity require actions within the family and that the Family Health Units are privileged spaces for the development of precautionary and educational practices aimed at promoting the health of all family members, in the perspective of comprehensive care, this study used Dorothea Orem's Theory of Self-Care as the conceptual basis. To this end, this research was based on the concept of self-care proposed by the author, who defines self-care as a human regulatory function to supply or guarantee the supply of materials necessary to continue life, growth, development and maintenance of human integrity. The requirements for self-care are actions to be performed by or for an individual with the aim of controlling human or environmental factors affecting human functioning or development. These requirements can be of three types: universal, developmental and health diversion ${ }^{(9)}$.

From this perspective, the following research question was elaborated: What nursing actions are used in the Family Health Strategy in the follow-up of overweight and obese children? The present study aimed to analyze the actions of nurses in the follow-up of the growth and development of overweight and obese children in the Family Health Strategy.

\section{Methods}

This is a qualitative study developed in five Family Health Clinics located in Program Area 3.1 of the city of Rio de Janeiro, which has a population of 886,511 registered users in the territory.

The Family Health Clinics, which are the setting of this study, were composed of 12 Family Health Teams, each consisting of a physician, a nurse, a nursing technician, six community health workers, and a dentist. Of these five units, two had the Family Health Su- 
pport Center with the following professionals: social worker, physical educator, nutritionist and psychologists.

Study participants were 12 nurses from the Family Clinics, who performed childcare consultations in the follow-up and development of children, including those overweight and obese. The inclusion criterion was having been working for more than one year and the exclusion criterion was being on vacation or any kind of leave in the data collection period.

Data collection took place through interviews, from July to October 2016, guided by a semi-structured script, directed to the objective of the study. The script for data collection was prepared by the authors, and a pilot test was performed to validate the questions with two nurses from a Family Health Clinic, which was not a study setting, and these data were discarded. All nurses were invited to participate in the study during their work schedule, and there was no denial of any of them nor did they request that their interview be withdrawn during the study. Interviews were conducted on days previously scheduled with participants, at lunch intervals or after working hours, in the participants' clinic rooms, for ensuring privacy and confidentiality. All the interviews were carried out by the first author of the article, who received training to perform them, and lasted an average of 12 minutes, being recorded in a digital medium, after acceptance and signing of the Informed Consent Form.

The empirical material generated in the interviews was treated by the thematic analysis method, following its three steps ${ }^{(10)}$. The first step consisted in the floating reading of the transcription of the interviews recorded in digital medium, being this material the textual corpus of the research. In the second stage, the material was explored with the identification of thematic units. In the third and last stage, the treatment and interpretation of the results was conducted.

The participants were identified with the letter $\mathrm{N}$, followed by the Arabic number corresponding to the order of the interview, for example, N1, N2 and so on. The study was conducted in accordance with the ethical standards set forth in the Brazilian research legislation involving human subjects and approved by the Ethics and Research Committee of the Municipal Health Secretariat of Rio de Janeiro, under opinion no 1,537,729 and Certificate of Presentation for Ethical Appreciation no 55450316,3,0000,5279.

\section{Results}

Of the 12 nurses, all were female, aged between 24 and 43 years, with time since graduation varying between two and twenty years, of whom $50.0 \%$ had been working for more than seven years in the Family Health Strategy, $25.0 \%$ for five years and the other $25.0 \%$ for one year.

From the analysis of the speeches, two thematic units emerged: Deficit in self-care of children and families with child overweight and obesity and Nurse's actions for self-care of children and families with child overweight and obesity.

\section{Deficit in self-care of children and families with child overweight and obesity}

In primary care, during childcare consultations, nurses carry out the nursing history, including food and family history, as well as growth follow-up, through an anthropometric evaluation, thus identifying those at risk or those already overweight and obese. In nursing consultations, we evaluate weight and height and evaluate the child's chart. We use the booklet and see whether the child is underweight, within a normal range, or overweight. By that instrument (child's booklet), I usually evaluate whether this child is overweight or not (N5). During the nursing consultation, I try to know the food history, whether there is a history in the children's family of obesity, diabetes, hypertension and through the parameter that is anthropometric evaluation, we measure weigh, height, check the body mass index and then we make an overall evaluation (N6). We usually have a procedure with all children when they come to childcare consultation. We measure the child's weight and evaluates according to the child's health booklet, which has a chart (N11).

The actions of nurses during the nursing con- 
sultation aimed at monitoring the growth of the children included the measurement and evaluation of anthropometric measures, such as weight, height, body mass index calculation, besides recording these values with interpretation of the result in the child health booklet.

Associated with this is the follow-up of human factors by means of the survey of the food history of the child and the other people in the family. Thus, given the information obtained, the nurses develop guidelines with the family in order to promote exclusive breastfeeding up to six months and healthy eating in childhood. Guidance should be provided from prenatal care to ensure breastfeeding. Sometimes the father and the mother are overweight and are not concerned about the child's feeding. I think we still have a greater responsibility to guide in the future, than only to identify children who are overweight (N12). Exclusive breastfeeding, healthy eating. Those who greatly influence the feeding of children are the grandmothers because they rush to encourage mothers to give formula milk (N7). So, first we perform a nutritional research of this child, evaluate whether this child is being exclusively breastfed, or whether other foods had already been introduced in children up to 6 months of age. If other foods had already been introduced ahead of time, we have to guide parents to do it right (N2).

The guidelines on breastfeeding, given by the nurses from the prenatal period, is a necessary requirement for the self-care of the family in promoting the growth and development of the child.

\section{Nurses' actions for the self-care of children and families with child overweight and obesity}

Participants' testimonies allowed us to identify that overweight and obese children and their families have a deficit in self-care, which is marked by the increased weight. In this sense, professionals demonstrated in their speeches the nursing actions for the care of these children. First, we see analyze the habits and then we make the guidelines showing her (mother) that we have a team, and the doctor and I, we elaborate the guidelines according to what the child has. If the child has high cholesterol, he/she will receive written guidance on what foods will increase weight and what to avoid (N11). If the child is very small, we give guidance for parents regarding the feeding offered to the child and, depending on the age, even physical activities, extracurricular activities (N4). Advising on physical activities, which will not only bring other benefits to children, in addition to social interaction, motor development, and everything else (N9).

Thus, nursing actions include written guidelines for family members and for children, depending on their age, regarding foods that can be consumed and which should be avoided. Guidelines on the importance of physical and extracurricular activities, including for child development, are also included in educational practice. E9 exemplified in her testimony the way she develops food guidance related to the importance of colored foods. There is a guideline we give: If it is a girl, the mother can put beets in the rice, the rice will turn to pink and she can say that is Barbie's rice; if it is a boy, the mother can put spinach and say it's Hulk's rice. We try to make the mother understand that children need to have a colored food. Having creativity in arranging the food or call the child together to choose which food to eat, because sometimes this encourages the child to eat properly (N9).

Therefore, the guidelines provided by the nurses are directed to the care in the selection of healthier, less caloric, and more colored foods, with different nutrients. There is also the encouragement to play during the guidance, by approaching the food of colors known by the children and their connection to characters of the children's imagination.

Participants also talked about health education actions they carried out in schools and in the unit itself, through the convocation of families for the formation of educational groups. We show videos to the kids at school. I even did a work on childhood obesity in our team's schools. For younger children, we do more playful activities on fruits, healthy foods and, during the consultation, guidelines to the children, the family members. We (nurses) always show the photos of how much sugar there is in the soda, in industrialized foods, how much salt and fat, during the consultation (N9). We usually convoke (family and children) for the groups (aimed at prevention of child overweight and obesity) to clarify, guide and show the reality. So, what we do not want for that child, what we expect for that child that we still have time to change, to prevent, even before even identifying overweight (N12). 
Family Health Strategy nurses carry out group activities with family and children to prevent overweight and obesity with the inclusion of playful strategies.

\section{Discussion}

A limitation of this research is that it was carried out in five Family Health Clinics from the same program area, in the city of Rio de Janeiro. Thus, it is necessary to research in other program areas of the city and in other Brazilian cities, where the socioeconomic levels and the clients' profile may vary and consequently demand new and different actions by the nurses. For this reason, it is not possible to generalize the data.

The registration and evaluation of anthropometric measures in the child's health booklet during the nursing consultation are a stimulus to self-care, focusing mainly on monitoring growth and development and preventing child health deviations, including overweight and obesity. These findings corroborate the scientific evidence that reinforces the importance of this practice with children at risk or not up to ten years of age, especially the evaluation of body mass index, since it allows determining adiposity and overweight, besides being predictive of obesity in adult life. Therefore, the record of body mass index by age and sex since birth is recommended ${ }^{(3)}$.

Another result was the use of the family history as a strategy for the identification of possible risk factors for child overweight and for the promotion of specific guidelines according to the situation found, which is consistent with the scientific literature on the subject. In this perspective, studies indicate the main risk factors to be analyzed: parents' overweight or obesity, with emphasis on the mother's obesity, even before pregnancy; physical inactivity, indirectly assessed by the number of hours the child watches television; absence of breastfeeding or early weaning and the family's dietary habits; and child caregivers' unhealthy eating habits ${ }^{(3,5)}$.

In Brazil, as in the United States, children of lower socioeconomic classes are more likely to develop overweight or obesity. Thus, similar to the nurses' reports, in this country, as a strategy to minimize the deleterious effects of childhood obesity, especially among poor, Latin-American and black children, educational interventions have been developed with families aiming at increasing the time of exclusive breastfeeding, excluding the consumption of sugary juices and beverages, increasing the number of sleeping hours, reducing the time spent watching television, changing the family diet with the inclusion of vegetables, and stimulating the practice of physical activities ${ }^{(1,11)}$.

In this sense, the actions of nurses in the Family Health Strategy should aim at the adoption of healthy eating habits by the family in order to preserve life and well-being, with a stimulus to self-care ${ }^{(8)}$, such as increasing consumption of fruit, vegetables and whole grains; limiting the consumption of high-fat and high-sugar foods (which have high energy density); avoiding and limiting the consumption of soda; establishing and observing meal times and avoiding doing them while watching television; reducing exposure to food advertising; reducing the size of food portions; and respecting the satiety of the child ${ }^{(3)}$.

Another nursing action of the nurse to be highlighted refers to the encouragement and maintenance of breastfeeding for the prevention of child overweight and obesity through guidelines during prenatal care. The World Health Organization and the United Nations Children's Fund recommend exclusive breastfeeding up to six months, extending up to two years in a complementary way, as an important measure to prevent future diseases, such as overweight. However, in Brazil, the duration of exclusive breastfeeding is still considered low and the early introduction of inadequate foods in children's diet, with a high glycemic index and composed of carbohydrates, is common, which predisposes to overweight and obesity ${ }^{(12)}$. This reinforces the need for educational practices in this area, according to the research findings.

It is worth mentioning that the family is responsible for the provision of food and the formation of the 
children's food habits; however, family members often yields to the child's pleas, allowing the regular intake of inappropriate food. Therefore, the family must be a constant target of nursing interventions aimed at productive self-care ${ }^{(8)}$, which occurs when the person demonstrates the ability to care for oneself and the other, so that the person can effectively contribute to the improvement of the child's food pattern, since prevention is the most efficient measure for weight control in childhood ${ }^{(5)}$.

An European research on the role of parents in child nutrition has identified that the intensity of their involvement in the implementation of weight control interventions is effective in preventing childhood obesity in the long term ${ }^{(13)}$. Thus, it is important that parents participate in promoting the child's health and building a healthy lifestyle.

Children who are already overweight and obese have lower capacity for self-care, which favors the maintenance of this health problem. Therefore, when there is self-care deficit, interventions and care with a focus on nursing knowledge, skills, and experience are necessary to level or surpass the demands to that specific period of the child's life.

In this context, the nursing actions described by the nurses referred to guidance on food and physical activities, both for the family and for the child, also in the school setting. In the actions aimed at children, the use of playful strategies was evidenced as a facilitating resource to approach this public. This result is in agreement with the literature that emphasizes the importance of the use of language and resources accessible to children in order to maintain, establish or improve the health, well-being and the care of oneself ${ }^{(8)}$. Therefore, playful strategies such as games, clipping and collage and stories have a positive effect on pre-school and schoolchildren regarding to the subject matter.

In the choice of healthy food, the literature recommends that children touch fruits and vegetables without any preparation to stimulate the sense of smell and touch and, when possible, that they assist in the preparation of meals. Healthy foods should be offered in colored preparations and, when possible, in playful formats of pets, flowers and others that are attractive to children ${ }^{(14)}$, which is in line with the playful strategies listed by the participants of this research.

The school can be considered a suitable place for the conduction of interventions with a stimulus to self-care, with the establishment of educational practices related to physical activities and food aspects. A study pointed out that this environment provides significant advantages, such as greater range of actions, high number of students receiving guidance at the same time, continuity of strategies over time, and the possibility of structural and operational changes. However, interventions in schools focusing on child overweight and obesity should last longer than six months for better consolidation of healthy habits among students ${ }^{(15)}$.

Therefore, actions between the Family Health Strategy nurses and the school should be developed through the School Health Program, which aims at permanent articulation of education and health, with emphasis on prevention, promotion, recovery, and maintenance of health, with a view to addressing vulnerabilities that compromise the full development of children and young people in the public school system ${ }^{(16)}$.

Also in schools, nurses should encourage greater access and availability of healthy foods, as well as the restriction of sugary beverages and ultra-processed foods. They can also stimulate the regular practice of physical activities in and out of school, together with physical education teachers and families, to encourage and increase the energy expenditure of these children. The advantages of moderate physical activity in children include lower cardio-metabolic risk, lower fat mass and greater physical (especially cardiopulmonary) capacity. In addition to these immediate results, physical activity increases the likelihood of becoming an active healthy adult, in addition to decreasing the risk of future health problems, such as fractures, me- 
tabolic syndrome, breast cancer, among others ${ }^{(5,15)}$.

A study carried out in a Primary Health Care Unit located in the city of Fortaleza, in the Northeastern region of Brazil, pointed out that overweight and obese children have an increased metabolic risk, mainly related to sedentary lifestyle, preference for fast foods and to low family income ${ }^{(17)}$. Therefore, it is important that nurses contribute to health education and self-care by promoting healthy environments and investigating the health of the child and the family during consultations.

Nursing actions in monitoring the growth and development of overweight and obese children in the Family Health Strategy have repercussions on the physical and psychosocial development of children that surpass the physical body, with an impact and improvement in social life, as in the prejudice suffered by them. These children, in addition to the deficit in self-care, have fewer friends, less affection from parents and worse school performance. With the experience of suffering through bullying ${ }^{(18)}$, both in the traditional way and in cyberbullying, children with obesity have little motivation to engage in physical activity, avoid healthy lifestyles, and may present suicidal ideation ${ }^{(7)}$.

\section{Conclusion}

Nursing actions are focused on the self-care of the child and the family, in the scenarios of the Family Health Units, at home and school, in order to prevent or minimize the effects of overweight and obesity in childhood and its repercussions for the adult life. The nurse, faced with the situation of overweight and obesity in childhood, needs to develop guiding actions for the child and family self-care and, when necessary, refer them to other health professionals, such as the physician and the nutritionist, so that together they can care for the child. The prevention of overweight and obesity still is an important action for the self-care of children and families seen in the Family Health Strategy.

\section{Acknowledgements}

We thank to the Escola de Enfermagem Anna Nery/Universidade Federal do Rio de Janeiro, in agreement with the Municipal Health Department of Rio de Janeiro - funding body of the Residence Grant of the author Adicéa de Souza Ferreira.

\section{Collaborations}

Ferreira AS and Moraes JRMM contributed to the project design, data collection, data analysis and interpretation, article writing and relevant critical analysis of intellectual content. Góes FGB, Silva LF, Broca PV and Duarte SCM contributed to the analysis and interpretation of the data, essay writing, relevant critical analysis of the intellectual content and approval of the final version to be published.

\section{References}

1. Russell CG, Taki S, Laws R, Azadi L, Campbell KJ, Elliott R, et al. Effects of parent and child behaviors on overweight and obesity in infants and young children from disadvantaged backgrounds: systematic review with narrative synthesis. BMC Public Health. 2016; 16:151. doi: https://doi. org/10.1186/s12889-016-2801-y

2. Salvador CCZ, Kitoko PM, G AMD. Nutritional status of children and adolescents: factors associated to overweight and fat accumulation. J Hum Growth. 2014; 24(3):313-9. doi: http:// dx.doi.org/10.7322/jhdg.88969

3. Ulbricht LC, Ferreira M, Esmanhoto E, Ripk WL. Prevalence of excessive body fat among adolescents of a south Brazilian metropolitan region and state capital, associated risk factors, and consequences. BMC Public Health. 2018; 18(1):312. doi: http://doi.org/10.1186/s12889018-5216-0

4. Marques MS, Silva JR, Lima CAG, Maia EMGC. Prevalência de sobrepeso e obesidade entre crianças de 7 a 10 anos atendidas em unidade de Estratégia Saúde da Família - ESF. Rev Bras Med Fam Comunidade. 2015; 10(37):1-9. doi: http:// rbmfc.org.br/rbmfc/article/view/1032/743 
5. Sahoo K, Sahoo B, Choudhury AK, Sofi NY, Kumar R, Bhadoria AS. Childhood obesity: causes and consequences. J Family MedP Rim Care. 2015; 4(2):18792.doi:http://dx.doi.org/10.4103/22494863.154628

6. Matsudo VKR, Ferrari GL M, Araújo TL, Oliveira LC, Mire E, Barreira TV, et al. Socioeconomic status indicators, physical activity, and overweight/ obesity in Brazilian children. Rev Paul Pediatr. 2016; 34(2):162-70. doi: http://dx.doi.org/ 10.1016/j.rpped.2015.04.003

7. Santos FDR, Vitola CB, Arrieira ICO, Chagas MCS, Gomes GC, Pereira FW. Actions of nurses and teachers in the prevention and combat of childhood obesity. Rev Rene. 2014; 15(3):46370. doi: http://dx.doi.org/10.15253/21756783.2014000300011

8. Oliveira VBCA, Veríssimo MLÓR. Children's health care assistance according to their families: a comparison between models of Primary Care. Rev Esc Enferm USP. 2015; 49(1):30-6. doi: http://dx.doi. org/10.1590/S0080-623420150000100004

9. McEven M, Wills E M. Bases teóricas de Enfermagem. Porto Alegre: Artmed; 2016.

10. Minayo MCS. O desafio do conhecimento: pesquisa qualitativa em saúde. São Paulo: Hucitec; 2013.

11. Reichert APS, Vieira DSV, Santos NCCB, Albuquerque TM, Collet N, Vaz EMC. Growth and development surveillance: analysis of records in the child health handbook. Cogitare Enferm [Internet]. 2016 [cited Jun 20, 2018]; 21(4):19. Available form: http://www.saude.ufpr.br/ portal/revistacogitare/wp-content/uploads / sites/28/2016/12/45256-190896-1-PB.pdf

12. Cloutier MM, Wiley J, Wang Z, Autherene Grant A, Gorin AA. The Early Childhood Obesity Prevention Program (ECHO): an ecologicallybased intervention delivered by home visitors for newborns and their mothers. BMC Public Health. 2015; 15(584):1-13. doi: https://doi. org/10.1186/s12889-015-1897-9
13. Contarato AAPF, Rocha EDM, Czarnobay SA, Mastroeni SSBS, Veugelers PJ, Mastroeni MF. Independent effect of type of breastfeeding on overweight and obesity in children aged 12-24 months. Cad Saúde Pública. 2016; 32(12):e00119015. doi: http://dx.doi.org/10.1590/0102-311x00119015

14. Kruk JJ, Kortekaas F, Lucas C, Jager-Wittenaar H. Obesity: a systematic review on parental involvement in long-term European childhood weight control interventions with a nutritional focus. Obesity Rev. 2013; 14(9):745-60. doi: http://dx.doi.org/10.1111/obr.12046

15. Sá SPC, Azeredo EA, Lavoyer CE. Actions on nutrition education with children in daycare university - representatives' and teachers' perception about the playful. Rev Pesqui Cuid Fundam online. 2014; 6(4):1419-36. doi: http://dx.doi. org/10.9789/2175-5361.2014.v6i4.1419-1436

16. Guerra PH, Silveira JAC, Salvador EP. A atividade física e a educação nutricional no ambiente escolar visando a prevenção da obesidade infantil: evidências de revisões sistemáticas. J Pediatr. 2016; 92(1):15-23. doi: http://dx.doi. org/10.1016/j.jped.2015.06.005

17. Martins TA, Freitas ASF, Rodrigues MIS, Filho RNV, Moreira DP, Mourão CML. Metabolic risk factors in children in Primary Health Care. Rev Baiana Enferm. 2018; 32:e26264. doi: dx.doi. org/10.18471/rbe.v32.26264

18. Borges F, Barreto MS, Reis P, Viera CS, Marcon SS. Perceptions and attitudes of children experiencing obesity. Rev Rene. 2018; 19:e3261. doi: dx.doi. org/10.15253/2175-6783.2018193261 